Note: This is a pre-copy-editing, author-produced PDF of an article accepted for publication in Journal of Psychiatric and Mental Health Nursing following peer review. The definitive publisherauthenticated version [McLaughlin DF, McKenna H, Leslie JC, Moore K and Robinson J (2006) Illicit drug users in Northern Ireland: perceptions and experiences of health and social care professionals. Journal of Psychiatric and Mental Health Nursing, 13(6), 682-686] is available online at http://www3.interscience.wiley.com/journal/118506499/toc

\title{
ILLICIT DRUG USERS IN NORTHERN IRELAND: PERCEPTIONS AND EXPERIENCES OF HEALTH AND SOCIAL CARE PROFESSIONALS.
}

\begin{abstract}
Over the thirty years of conflict, Northern Ireland escaped the worst excesses of illegal drug trafficking and usage. This was in large part due to the 'policing' of local community crime by paramilitaries. However, since the first 'cease-fire' in 1994 the province has witnessed a dramatic and unprecedented rise in the availability of illicit drugs. This increased availability reflects rising consumption of these drugs in the province. The aim of this study was to explore the perceptions that a sample of health and social care professionals' hold of illicit drug users in Northern Ireland. A survey methodology was employed. Community settings across Northern Ireland WERE ACCESSED. Focus groups and face-to-face interviews WERE EMPLOYED AS DATA COLLECTION METHODS. Thirty-five health and social care professionals took part in this study. Thirty-two took part in six focus groups; three respondents underwent one-toone interview. The participating professionals reported to have little or no education or training in the care and treatment of illicit drug users. Some stated that they would reject the offer of education and training in this area to prevent contact with illicit drug users. Many displayed strongly negative views of this client group, often expressing a preference not to care for or treat these people, preferring all their care to be given by
\end{abstract}


specialists in illicit drug treatment. These findings indicate that most of the health and social care professionals who took part in this study appear unprepared and unwilling to meet the challenge of caring for illicit drug users. The findings will be of interest to service providers within and outside the United Kingdom.

Key Words Health and Social Care Professionals, Illicit Drug User, Perceptions, Experiences, Focus Groups/Interviews, Northern Ireland. 


\section{Introduction}

Since the first 'cease-fire' in 1994, Northern Ireland has witnessed a dramatic and unprecedented rise in the availability of and use of illicit drugs (McLaughlin et al., 2000; McElrath, 2002).

There is evidence from the Addicts' Index that more people are developing significant problems due to their use of illicit drugs (McLaughlin et al., 2000). This is all the more alarming as this index only refers to those individuals who are in contact with statutory services. Some authors have argued that these FIGURES are only the 'tip of the iceberg', with many more people using these drugs but WHO CHOOSE not to avail of services (McEvoy et al., 1998). Another indicator of the growing illicit drug problem in Northern Ireland was the establishment of its first pharmacy-based needle exchange scheme in April 2001 (Drugs and Alcohol Strategy Team, personal communication, 2002).

Due to the relative recency of the drug culture in Northern Ireland, health and social care professionals have had limited opportunities to develop knowledge and skills for the care and treatment of persons with an illicit drug problem. The combination of many people with illicit drug problems with few knowledgeable and skilled professionals has potentially disastrous implications (McLaughlin et al., 2000).

McLaughlin and Long (1996) completed a comprehensive review of the literature on this topic and found that in established areas of illicit drug use many professionals from different backgrounds and indeed countries held negative views of illicit drug users. 
They reported research that showed South African Nurses linked illicit drug use to a failing of character and a weak personality and some General Practitioners in England who felt the courtroom, not the consulting room, was the best place to deal with people that use illicit drugs. In fact they reported nurses who should humanise health care dehumanising people that use illicit drugs.

A comprehensive review of the literature on professionals' perceptions of illicit drug users uncovered only one Northern Ireland study. This was a major survey of nurses' attitudes to AIDS. Its findings showed that $37 \%(n=480)$ of the nurses believed that long prison sentences should be imposed on illicit drug users (Melby et al., 1992). The present study examined the views and experiences of Northern Ireland health and social care professionals towards illicit drug users.

\section{Method}

The aim of this study was to explore the perceptions and clinical experiences of health and social care professionals towards illicit drug users. Because of the exploratory and sensitive nature of this study, data were collected using focus groups and one-to-one interviews (Lee, 1993). The focus group approach has been described as "group discussions organised to explore a specific set of issues" (Krueger, 1998). Krueger referred to it simply as a process of group interaction that serves to generate data for analysis. Albrecht et al (1993) cautioned that these same group processes could inhibit participants in focus groups, especially the fact they are discussing their views in the presence of others. 
The interview has been described as a method of data collection in which the interviewer asks questions of the respondent; it can produce data that can give a rich and in-depth understanding of the issue under investigation (Polit and Beck, 2004). The interview can also prove challenging in that the interviewee can feel intimidated (Lee, 1993). Due to the nature of the topic under investigation and the desire to gain a rich understanding of the views of professionals it was decided to employ both focus groups and interviews as data collection methods.

\section{Participants}

To be included in the sample participants had to be a health or social care professional, have clinical experience with people that use illicit drugs, as defined in the Misuse of Drugs Act (1971), agree to take part in the study and agree to be audio taped. Purposive sampling was used. This means that respondents were selected to suit the purpose of the study and included those who it was perceived could contribute to the discussion from their specific professional background (Polit and Beck, 2004).

In total thirty-five professionals took part in this study with thirty-two participating in six focus groups. They included nine nurses, fourteen general practitioners (GPs), three health visitors, three pharmacists, a social worker, a health promotion worker and a health centre manager. Three staff were interviewed individually, as they could not attend arranged focus groups, they were two GPs and a health visitor. 


\section{Research instrument}

Following a comprehensive review of the literature and a pilot study, an interview schedule was designed incorporating the following questions:

- What has been your professional experience with illicit drug users?

- Do illicit drug users differ from other clients you see?

- If they do, in what way do they differ?

- How do you think the continued criminalisation of illicit drug users affects their care and treatment?

- Who do you think should care for illicit drug users?

- Do you feel you have any training needs in relation to illicit drug users?

- If so, what are those needs?

- How do you think illicit drug users perceive health professionals?

- Are there any other issues you would like to discuss?

These questions formed a discussion guide for the focus groups and interviews. Participants were allowed and encouraged to raise other issues of pertinence to the research topic.

\section{Ethical Issues}

There are specific ethical challenges unique to focus group methodology (Polit and Beck, 2004). This is because focus group participants disclose personal information not solely to the researcher but also to other focus group members. In addition, as professionals were being asked to speak about a challenging group of clients that have been 
marginalized and whose behaviour is criminalised, the assurance of informed consent and confidentiality were core ethical issues within the study. In addition, participants were made aware that they could withdraw from the study at any time without detriment. All participants gave their consent to take part in the study.

\section{The Data Collection Process}

Careful preparation is vital for the interview/focus group to run smoothly and successfully (Polit and Beck, 2004; Morgan, 1998). A full introductory statement was made prior to the data collection process commencing. All present gave their consent to take part in the study. The researcher explained that he hoped to audiotape the discussion, a common approach to recording focus group data (Krueger, 1998). When the discussion was complete and all the questions were answered and participants' queries addressed, the researcher thanked the participants and ended the discussion.

\section{Data analysis}

All the interviews and focus groups were audiotaped, transcribed and subjected to thematic content analysis using Burnard's (1991) guidelines. For example, each transcript was read a number of times and the content was organised into general themes (Polit and Beck, 2004). The questions posed to participants were used as a means to structure the thematic framework, this is recognised as a sound method to ANALYSE focus group data (Krueger, 1998). 


\section{Results}

A powerful theme to emerge was that some professionals did not want to be involved in the treatment and care of these clients. A GP made this very clear by stating:

"Difficult I suppose, difficult I'm (pause) I would prefer to run a mile rather than, they're not exactly the type of patient that you would want to accept onto your list, because generally speaking there is a perception that there is going to be a lot of hard work with them..." (Participant 14,

\section{Focus Group 3)}

A treatment room nurse also expressed a negative view of this group of people stating:

"I think they are very devious, and it doesn't matter how they are going to achieve, they will achieve it...they are very clever and very manipulative."

\section{(Participant 1, Focus Group 1)}

Not all professionals held negative views of illicit drug users. A health visitor spoke in compassionate terms showing empathy for what she saw as a marginalized group of people:

"Maybe initially before you got to know them you had preconceived ideas...about what drug abusers were like, really after you worked with them for quite awhile you realise most of them seemed to come from backgrounds of either abuse themselves or quite horrific backgrounds where you could really, you could feel sorry for them and 
realise why they ended up where they did, so it was quite good." (Participant 27, Focus

\section{Group 6)}

A GP felt that a lack of education about the illicit drug problem was central to a lot of the difficulty health and social care professionals have in this area:

“I think it's a lack of education not knowing about the drug problem reading GP magazine 'GP' attacked in surgery' you know 'surgery puts up fences because of drug users' whatever you know 'GPs hold surgery in police station', you know to me is where a lot of GPs are coming from it's ignorance”(Participant 18, Focus Group 3)

The lack of training and education opportunities for health and social care professionals in this area was highlighted by the fact that a treatment room nurse had gained her knowledge from a talk given to parents at her child's primary school:

"I actually had the talk in a primary school a few months ago as a parent, you know from the drug people and it was fascinating because I had never seen an illicit drug in my

\section{life." (Participant 8, Focus Group 2)}

Some of the professionals felt that education and training on the topic could possibly be dangerous. Their fear relates to the possibility that being perceived as experts could attract illicit drug users to their surgery. Also, there was a view that if they were trained, their colleagues would avoid this client group, leaving the trained professional to take more and more of the workload. A GP summed this sentiment up as follows: 
“..speaking as a general practitioner I would have a fear that if you became the trained practice that suddenly all the drug addicts in the area are diverted to you." (Participant

\section{7, Focus Group 2)}

Another strong theme to emerge was one of pessimism about the care and treatment of illicit drug users, a health visitor stated:

“..you always seem to come out feeling very despondent and that your best efforts are not umm really they are not really listening to you.” (Participant 3, Focus Group 1)

However, not all professionals had such negative expectations. A GP had experienced very positive results from treating people with illicit drug problems:

"We certainly have had a number of successes with guys who have been on heroin and been able to stop..” (Participant 33, One-to-One Interview)

The issue of who should care for illicit drug users produced some strong views from those taking part in this study. Interestingly, at no point did any professional ever suggest all the care of illicit drug users should be provided by the primary care sector. One GP was very firm in his conviction that the specialist services were the best place to care for illicit drug users:

"I think that drug users and especially heroin users are very challenging people and the best place to care for them is the specialists who have more time and experience with this group of people, I do not think general practice is the best place to care for them."

\section{(Participant 25, Focus Group 5)}

Please use the following citation: McLaughlin DF, McKenna H, Leslie JC, Moore K and Robinson J (2006) Illicit drug usere in Northern Ireland: perceptions and experiences of health and social care professionals. (Author postprint) in Journal of Psychiatric and Mental Health Nursing, 13(6), 682-686 [Accessed: (date) from www.drugsandalcohol.ie] 
One treatment modality that was suggested on a number of occasions was that of shared care, WERE THE CARE OF AN ILLICIT DRUG USER IS SHARED BY THE PRIMARY CARE TEAM AND THE SPECIALIST DRUG SERVICES. A social worker working with people with alcohol and illicit drug problems felt it was vital that GPs were involved in a degree of shared care, stating:

"In my experience, well I look at what we are trying to do in (names towns) and what we have achieved there is a shared care model and that seems to work. I think it is important for the GPs to be involved as that is the person you see first, so with that if GPs had an understanding of what to prescribe and the symptomatic relief or replacement in the short term but then know the mechanism that are there to refer.." (Participant 17,

\section{Focus Group 3)}

Many participants could not 'picture' the person with an illicit drug problem as being able to empathise with a professional. For example, a pharmacist stated:

"I don't think they have any real views of us as long as they get what they want."

\section{(Participant 5, Focus Group 1)}

Finally one GP issued a 'warning' to colleagues stating:

"But ah, I mean my ethical stand point is what the GMC says, which is that we are not allowed to distinguish between people because of their lifestyle and in fact the GMC says that if you refuse to look after someone because of their lifestyle, you could be found to be guilty of serious professional misconduct. 
And I mean they certainly do need help." (Participant 35, One-to-One

\section{Interview)}

\section{Discussion}

The findings from this study show many of the professionals who participated held entrenched negative views of people that use illicit drugs. These same professionals admit to having little knowledge or skills to assist users with their problems. This finding supports results from other studies in the United Kingdom that highlighted the negativity and paucity of professional preparation to deal with this client group (McLaughlin et al., 2000; Mistral and Velleman, 2001).

There was a small number of professionals who expressed positive views of illicit drug users and who were willing to care for them. This finding reflects previous studies showing that a minority of professionals view these clients in a positive light (Mistral and Velleman, 2001; Ford and Ryrie, 2000).

Most of the professionals surveyed called for the care of illicit drug users to be undertaken exclusively by specialist services. The impression obtained was that this could remove the burden of these clients from the primary care service, a trend also identified by Mistral and Velleman (2001).

Most of the participants in the study appeared unable or unwilling to empathise with the person who used illicit drugs. This lends support to other studies which reported that 
health professionals stigmatise illicit drug users, often perceiving them incapable of anything other than seeking and taking illicit drugs (McLaughlin et al., 2000).

\section{Limitations}

A possible source of bias with focus groups is the potential domination by one or two individuals leading to skewed results. While this was a concern, the focus group facilitator was very experienced in-group work and there was no evidence of this bias within the focus group discussions.

By the very nature of the methodology, no attempt is made to generalise the findings to other professionals or settings outside the study. Nonetheless, it is important to note that the results reflect those of previous national and international research studies. Noting that the same issues arose again and again from different participants in different groups at different times and locations helps to confirm the emerging themes.

The fact that three participants who were unable to attend the focus groups were interviewed may be an added source of bias. Interestingly, a GP, one of the interviewees, was extremely positive about his work with illicit drug users. It is not possible to know whether being interviewed altered the interviewees' responses or whether they would have responded differently in a focus group setting. Similarly, if they had, participated in the focus groups the impact that this may have had on the responses of others is unknown. Finally, it is unknown if the presence of different professionals in the focus groups influenced the response and participation of others. 


\section{Conclusions}

Based on the findings the following conclusions and recommendations appear warranted.

They relate to only those participants who took part in the study:

- Many participants in this study have low regard for people with illicit drug problems who present themselves for help;

- Many participants admitted to a lack of basic knowledge and skills and would reject an offer of education or training as a means of updating their knowledge and skills, indicating that this might attract illicit drug users;

- In the main participants felt deeply pessimistic about this group of people;

- Mostly participants in this study did not want to give care either solely or in combination with specialists to illicit drug users. Rather they preferred that specialists provide all the care to this group of people,

- A small number of participants gave good care and wanted to be involved with illicit drug users;

- Most participants did not have any idea how the people with an illicit drug problem perceived them. Many were unable to empathise with illicit drug users and their difficulties.

\section{Recommendations}

In a post conflict situation, Northern Ireland has a growing illicit drug problem with more people using such substances. Through their professional codes conduct health and social care professionals are duty bound to give direct help and guide patients to specialist help if needed. Most participants in this study were unprepared and unwilling 
to meet this emerging challenge. Health and social care professionals must be provided with education and training in the care of people with illicit drug problems. They also need incentives and encouragement to give care to this challenging and marginalised group of people.

\section{Acknowledgements}

We are indebted to the people who agreed to take part in the research. Without them this study would not have been possible. We are also indebted to DHSSPS, An Bord Altranais/NBNI for their help and support.

\section{References}

Albrecht, T.L., Johnson, G.M., Walther, J.B. (1993) Understanding communication processes in focus groups. In Morgan, D.L. editor Successful Focus Groups: Advancing the State of the Art. Newbury Park: SAGE

Burnard, P. (1991) A method of analysing interview transcripts in qualitative research. Nurse Education Today 11 (6) 461-466.

Ford, C., Ryrie, I. (2000) A comprehensive package of support to facilitate the treatment of problem drug users in primary care: an evaluation of the training component. International Journal of Drug Policy 11, 387-392.

Great Britain (1971) Misuse of Drugs Act Chapter 38. London: HMSO.

Please use the following citation: McLaughlin DF, McKenna H, Leslie JC, Moore K and Robinson J (2006) Illicit drug users in Northern Ireland: perceptions and experiences of health and social care professionals. (Author postprint) in Journal of Psychiatric and Mental Health Nursing, 13(6), 682-686 [Accessed: (date) from www.drugsandalcohol.ie] 
Krueger, R.A. (1998) Analysing and Reporting Focus Groups Results: Focus Group Kit

6. London: SAGE Publications.

Lee, R.M. (1993) Doing Research on Sensitive Topics. London: SAGE Publications.

McElrath, K (2002) Prevalence of Problem Heroin Use in Northern Ireland. Belfast: HMSO

McEvoy, K., McElrath, K., Higgins, K. (1998) Does Ulster still say no? Drugs, politics, and propaganda in Northern Ireland. Journal of Drug Issues 29, 127-154.

McLaughlin, D. F., Long, A. (1996) An extended literature review of health professionals' perceptions of illicit drugs and their clients who use them. Journal of Psychiatric and Mental Health Nursing 3, 283-288.

McLaughlin, D.F., McKenna, H., Leslie, J.C. (2000) The perceptions and aspirations illicit drug users hold toward health care staff and the care they receive. Journal of Psychiatric and Mental Health Nursing 7, 435-441.

Melby, V., Boore, J.R.P., Murray, M. (1992) Acquired immunodeficiency syndrome. Knowledge and attitudes of nurses in Northern Ireland. Journal of Advanced Nursing 17, 1068-1077.

Please use the following citation: McLaughlin DF, McKenna H, Leslie JC, Moore K and Robinson J (2006) Illicit drug user6 in Northern Ireland: perceptions and experiences of health and social care professionals. (Author postprint) in Journal of Psychiatric and Mental Health Nursing, 13(6), 682-686 [Accessed: (date) from www.drugsandalcohol.ie] 
Mistral, W., Velleman, R. (2001) Substance-misusing patients in primary care: incidence, services provided and problems. A survey of general practitioners in Wiltshire. Drugs: Education, Prevention and Policy 8, 61-72.

Morgan, D.L. (1998) Planning focus groups: focus group kit 2. London: SAGE Publications.

Polit, D.F., Beck, C.T. (2004) Nursing Research: Principles and Methods. $7^{\text {th }}$ ed. Philadelphia: Lippincott Williams \& Wilkins. 